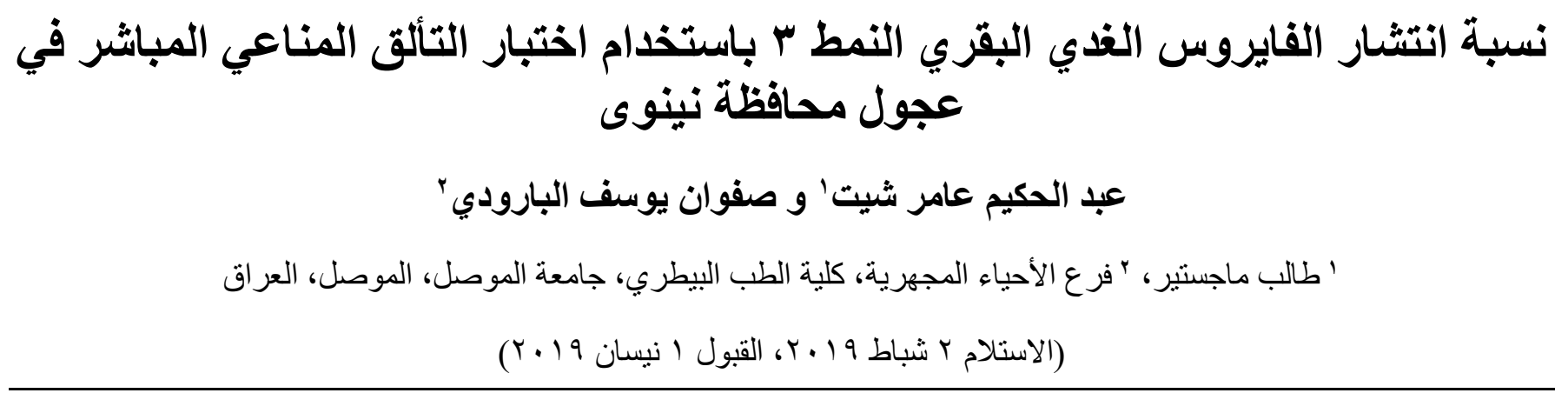

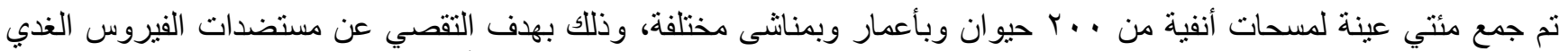

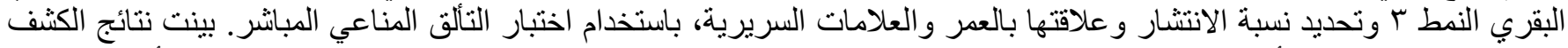

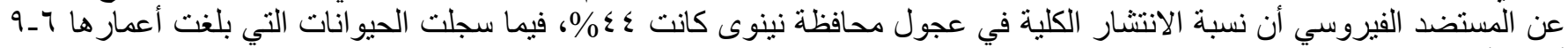

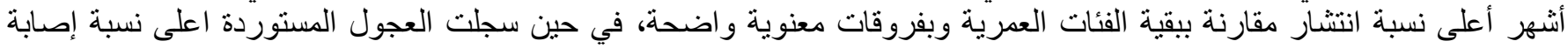

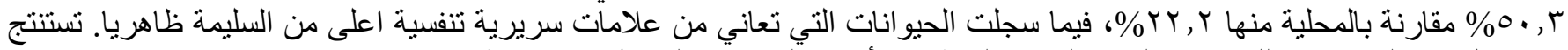

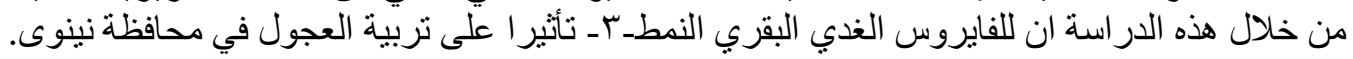

\title{
Prevalence of the bovine adenovirus type 3 by using direct fluorescent antibody technique in calves in Nineveh province
}

\author{
A.A. Sheet ${ }^{1}$ and S.Y. Albaroodi ${ }^{2 *}$ \\ ${ }^{1}$ MSc students, ${ }^{2}$ Department of Microbiology, College of Veterinary Medicine, University of Mosul, Mosul, Iraq \\ *Email: Safwanalbaroodi@yahoo.com
}

\begin{abstract}
A total of 200 samples were collected from the calves for different ages from local and exotic breed by using nasal swabs, to investigate the prevalence of the bovine adenoviruses. The results showed that about $44 \%$ of the examined calves gave positive to immunofluorescence test, and the calves aged 6-9 months showed highly significant prevalence compare with other ages. The prevalence of virus infection in the exotic breed was $50.3 \%$ compared with local breed $22.2 \%$. The calves with respiratory affections showed a higher prevalence from those which seem to be healthy. The current study concluded that the bovine adenovirus-type 3-virus has an effect on the breeding of calves in Nineveh Governorate.
\end{abstract}

Keywords: Bovine Adenovirus Type 3, Direct Fluorescent Antibody, Nineveh province Available online at http://www.vetmedmosul.com, (C) 2020, College of Veterinary Medicine, University of Mosul. This is an open access article under the CC BY 4.0 license (http://creativecommons.org/licenses/by/4.0/).

بأ nonenveloped المقدمة

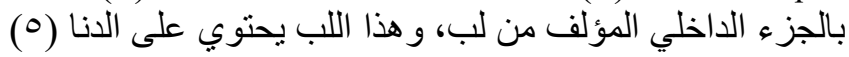

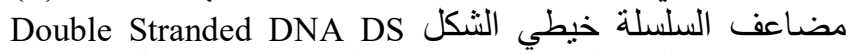

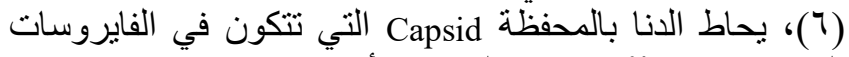

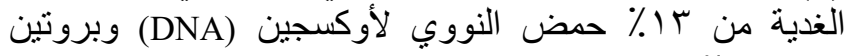

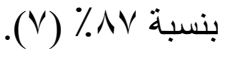

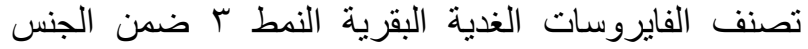
Mastadenoviruse (Y) Adenoviridae

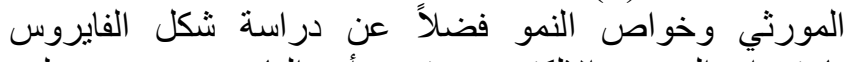
باستخدام المجهر الإلكتروني تبين أن الفيروس غير فير مغلف 
تمثلت، بإفرازات أنفية متباينة الثدة والنوع في حين كان العدد

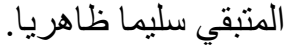

\section{جمع المسحات من الأنف}

تم جمع المسحات (من الأنف للحيو الانات التي استخدمت في

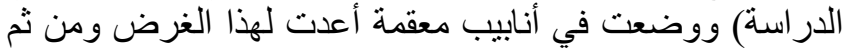

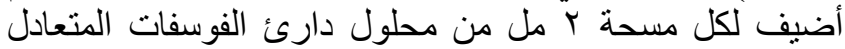
ومن ثم نقلت الى أنابيب زجاجية أخرى معقمة وضعت دارئ هذئ

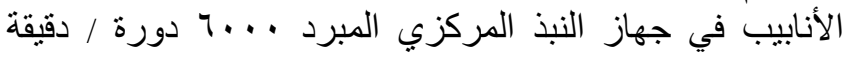

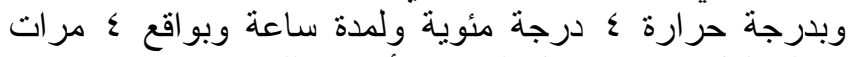

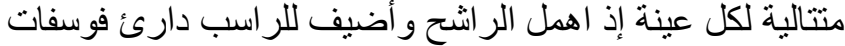

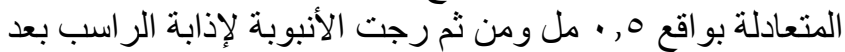

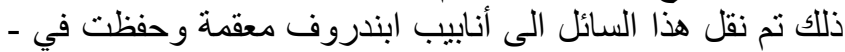

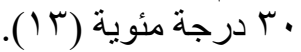

\section{الكثف عن المستضد الفيروسي في المسحات الأنفية باستخدام

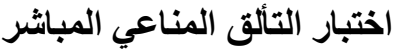

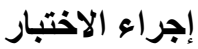

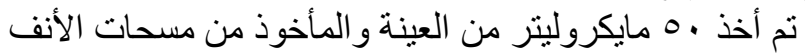

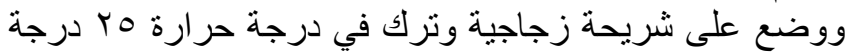

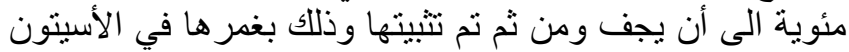

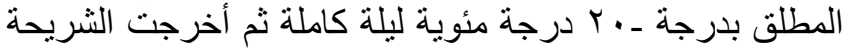

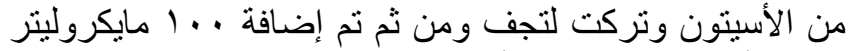

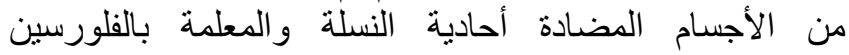

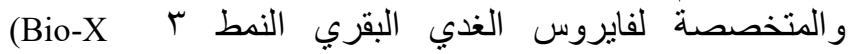

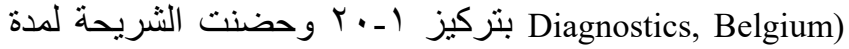

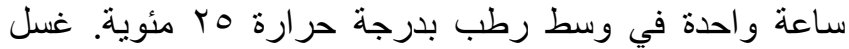

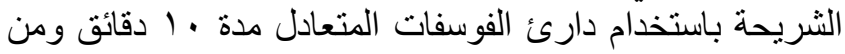

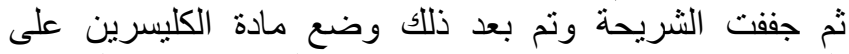
الثريحة ومن ثم وضع غطاء شريحة عليها. فحصت الثرات الثريحة

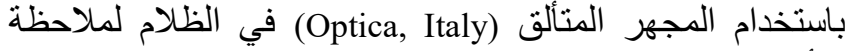
التألق لمعر فة العينات الموجبة و العينات السالبة (7 (1).

تم تحليل النتائج إحصائياً باستخدام مربع كاي وباستخدام

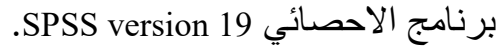
النتائج

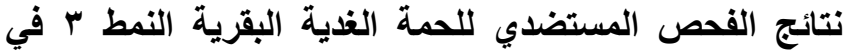

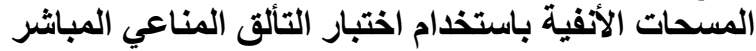

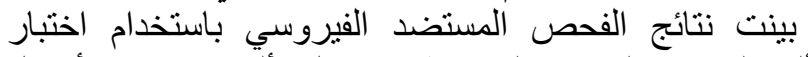
التألث المناعي المباشر الذي يظهر بشكل تألثق مناعي (الأشكال

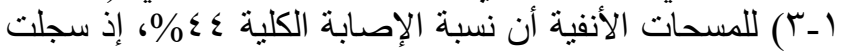

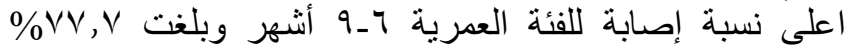

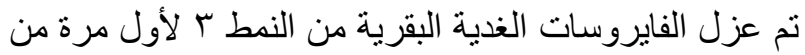

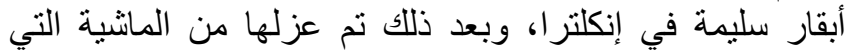

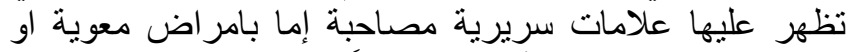

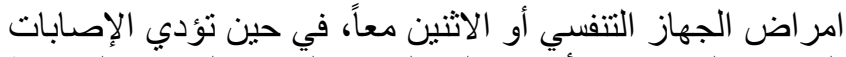

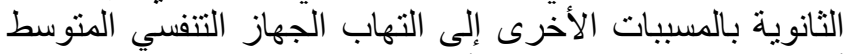

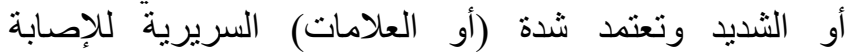

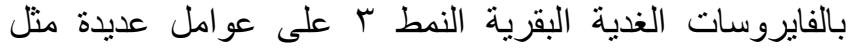

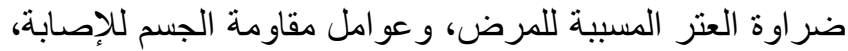

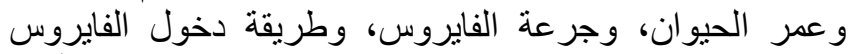

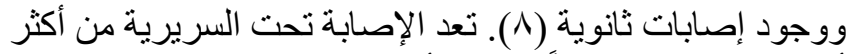

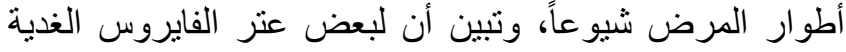

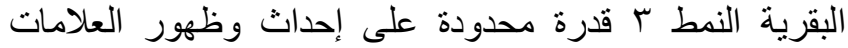

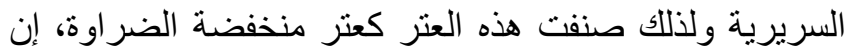

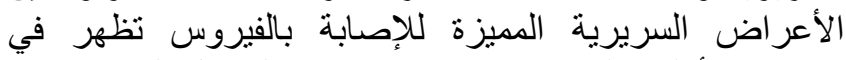

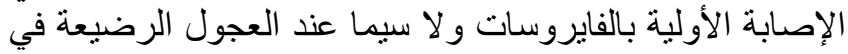

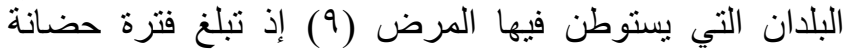

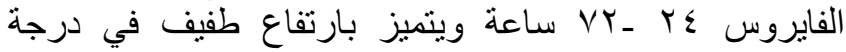
الحرارة (·) (1). (1).

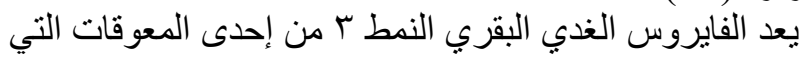

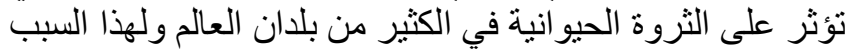

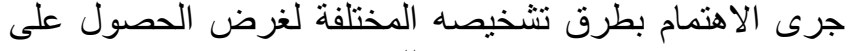

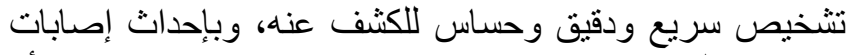

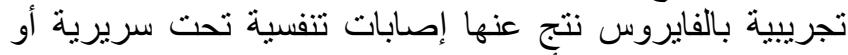

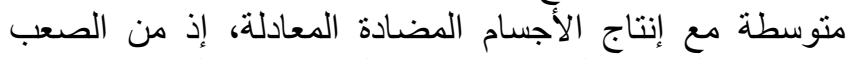

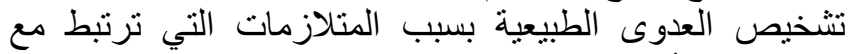

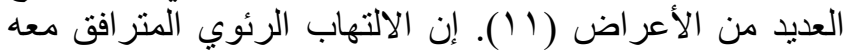

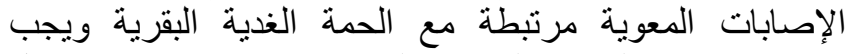
تمييزها عن الالتهاب الرئوي المرتبط مع فئه فايروس الإسهال

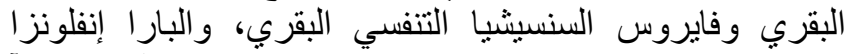
parainfluenza

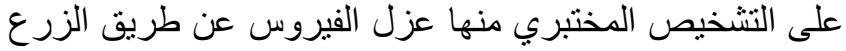

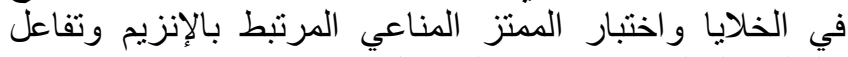

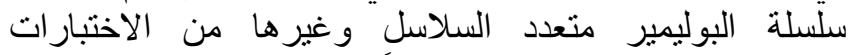

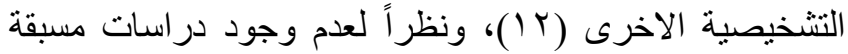

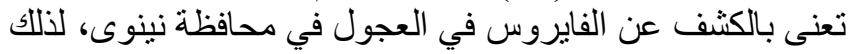
تم اقترح هذه الدراسة للكثف عن المستضد الحئ الحمي باستخدام تقنية

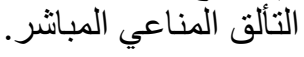

المواد وطر ائق العمل

$$
\text { حيوانات الدراسة }
$$

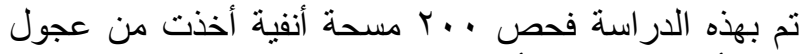

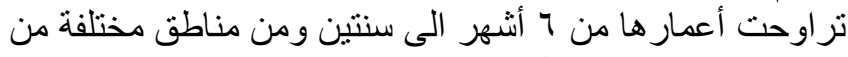
محافظة نينوى كان البعض منه يعاني من علامن أنهات سريرية 


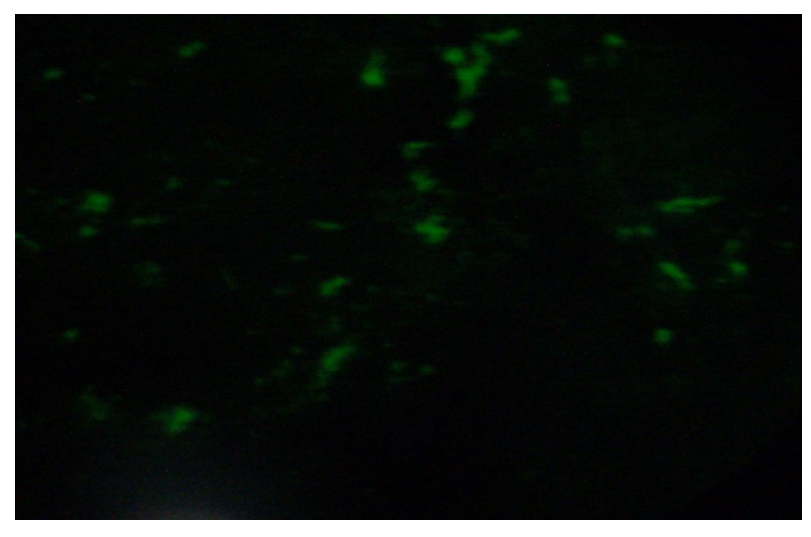

الشكل r: صورة مجهرية نوضح النتيجة السلبية لاختبار التألق

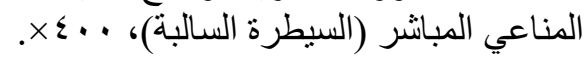

يتبين عند إيجاد العلاقة بين نسبة الإصابة ومصدر العجول

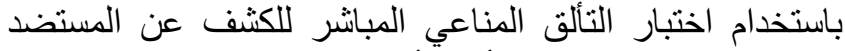

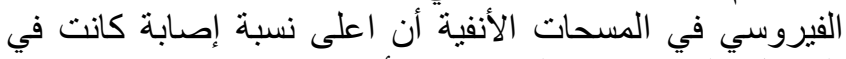

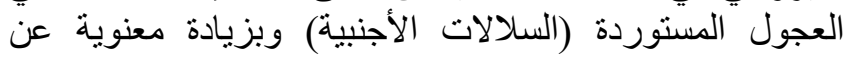
السلالات المحلية منها (جدول (بلول)

الجدول r: يبين علاقة نسبة الاصابة بفايروس الغدي البقري

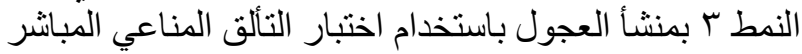

\begin{tabular}{|c|c|c|}
\hline 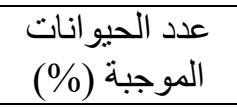 & عدد الحيو انات & المنشَاً \\
\hline$a(\%, r, Y) \perp$. & $\leqslant 0$ & \\
\hline $\mathrm{b}\left(\%{ }^{\circ} \cdot\right) \vee \wedge$ & 100 & مستورد \\
\hline
\end{tabular}
الحروف المختلفة تعني هنالك اختلاف معنوي (P<0.05).

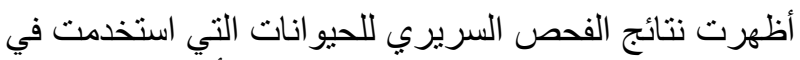

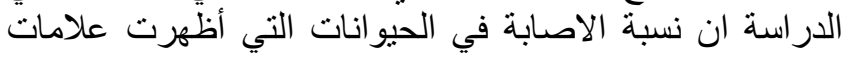

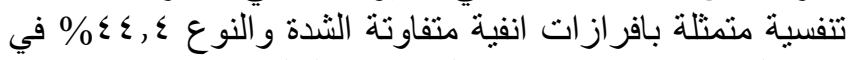

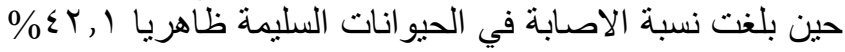

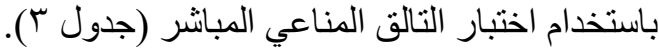

الجدول ؟ب: علاقة نسبة الإصابة بفايروس الغدي البقري النمط ؟ باستخدام اختبار التألق المناعي المبانشر

\begin{tabular}{|c|c|c|}
\hline عدالمد الحيو (\%) & عدد الحيو انات & المنشاً \\
\hline $\mathrm{a}(\% \varepsilon \varepsilon, \xi) \vee r$ & 174 & إفرازات أنفية \\
\hline$a(\% \leq r, 1) \backslash 7$ & rᄉ & سليمة ظاهريا \\
\hline$(\% \leq \varepsilon) \wedge \wedge$ & r... & المجموع \\
\hline
\end{tabular}

وكانت هناللك زيادة معنوية مقارنة بيقية المجاميع وتناقصت النسبة بتقدم العمر (الجدول ( ) ).

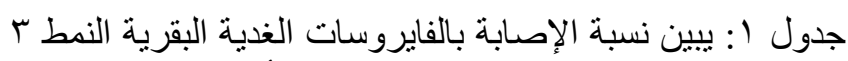

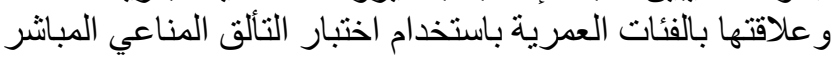

\begin{tabular}{|c|c|c|}
\hline 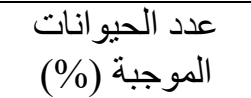 & عدد الحيو انات & الأعمار \\
\hline$a(\% \vee V, \vee V) \Gamma^{\prime}$ & $\leqslant 0$ & 7ـ9 أشهر \\
\hline $\mathrm{b}\left(\%{ }^{\prime}(\tau, \tau) r \tau\right.$ & VI & من · ا أششهر - سنة \\
\hline$b\left(\%{ }^{\prime},, V\right) r$. & ז & من 1 ـ 0, 1 سنة \\
\hline b $(\% r, r) \vee$ & $r_{1}$ & من 0, 0 - r سنة \\
\hline$(\% \leq \varepsilon) \wedge \wedge$ & r.. & المجموع \\
\hline
\end{tabular}

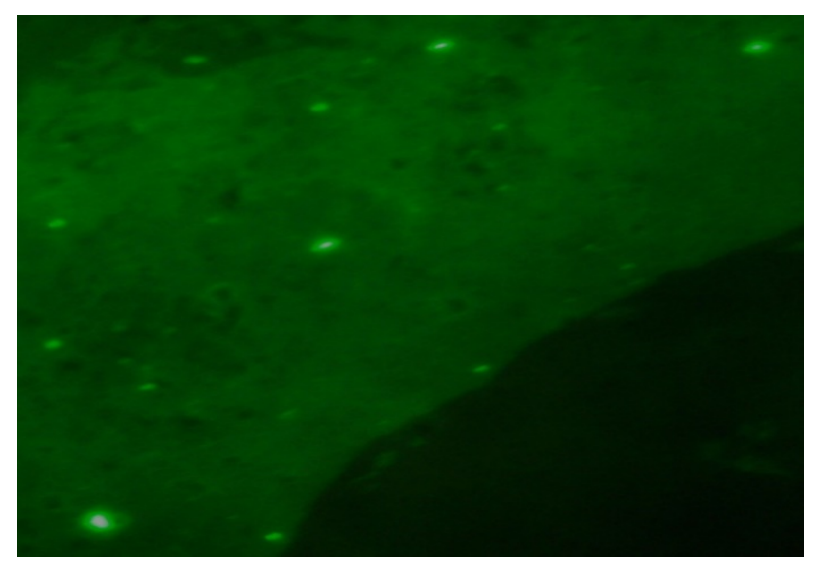

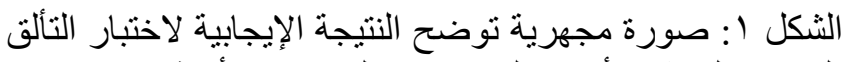
المناعي المباثر لأحدى العينات من المسحات الأنفية، . . ع ×.

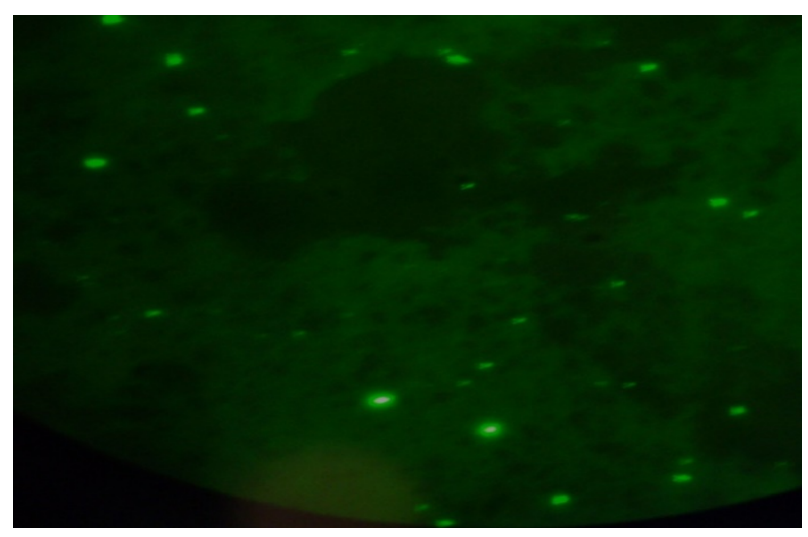

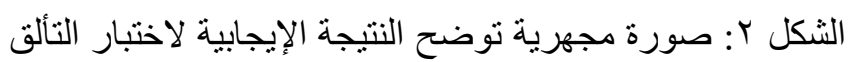
المناعي المباشر (السيطرة الموجبة)، ، . . ؟×. 


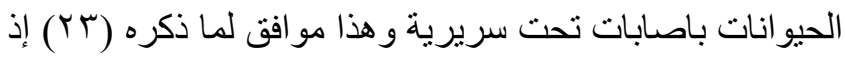
ذكر ان معظم الاصابات بالفايروس الغدي تكون تحت سرئ سريرية.

الاستثتاجاث

نستتنج من خلال هذه الدراسة ان نسبة انتشار الفايروس

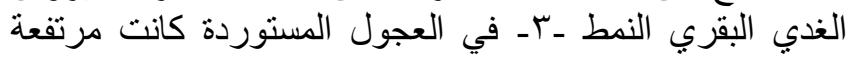

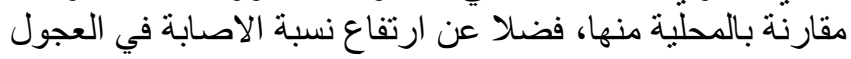

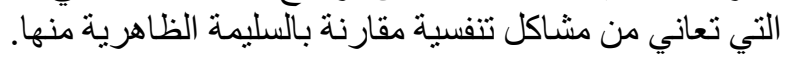

\section{شكر وتقدير}

الثكر والتقدير الى عمادة كلية الطب البيطري وفرع الأبداء

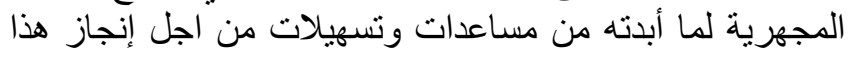

\section{المصادر}

1. Zhu Y, Yu Z, Cai H, Gao Y R, Dong X M, Lili Z, Shi H F, Meng Q F, $\mathrm{Lu} \mathrm{C}$, Xue F. Isolation identification and complete genome sequence of a bovine adenovirus type 3 from cattle in China. Virol J. 2011;8(557):18. doi: $10.1186 / 1743-422 X-8-557$

2. Elgadi M. Molecular cloning and restriction endonuclease analysis of bovine adenovirus type 3 [MSc thesis]. Ontario: Brock University; 1993. p.20-23. DOI: $10.1159 / 000150272$

3. Gaba A. Role of polypeptide pVIII In bovine adenovirus (BAdV)-3 lifecycle [PhD dissertation]. Saskatchewan: University of Saskatchewan; 2016. p.40-49. http://hdl.handle.net/10388/7553

4. Russell WC. Adenoviruses: Update on structure and function. J Gene Virol. 2009;90:1-20. doi: 10.1099/vir.0.003087-0.

5. Imperiale MJ. The amphipathic helix of adenovirus capsid protein VI contributes to penton release and postdentary sorting. Am Soci Microbiol J Virol. 2014;92:1-23. doi: 10.1128/JVI.02257-14

6. Marco B, Palma SD, Joost CL, Moyer VS, Reddy RN, Albert JR. Adenovirus composition proteolysis and disassembly studied by in depth qualitative and quantitative proteomics. J Biol Chem. 2014;289:1142111430 doi: $10.1074 / j b c . M 113.537498 .$.

7. Whipple MJ. Development of an enzyme-linked immunosorbent assay for the serologic diagnosis of bovine adenovirus Type 3 [MSc thesis]. Oregon: College of Veterinary Medicine; 1992. p. 11-14. https://ir.library.oregonstate.edu/concern/graduate_thesis_or_dissertatio $\mathrm{ns} / 8 \mathrm{c} 97 \mathrm{kt} 95 \mathrm{c}$

8. Mittal SK, Tikoo SK, Donkersgoed JV, Beskorwayne T, Godson DL, Babiuk LA. Experimental inoculation of heifers with bovine adenovirus type 3. Can J Vet Res. 1999;63:153-156. https:/www.ncbi.nlm.nih.gov/pmc/articles/PMC1189536/

9. Paterson CP. Molecular characterization of $52 \mathrm{k}$ protein of bovine adenovirus type 3 [PhD dissertation]. Saskatchewan: University of Saskatchewan; 2010. p.78-79. http://hdl.handle.net/10388/etd08252010-105314

10. Narita M, Yamada M, Tsuboi T, Kawashima K. Immunohistopathology of calf pneumonia induced by endobronchial inoculation with bovine adenovirus 3. Vet Pathol. 2002;39:565-571. https://doi.org/10.1354/ vp.39-5-565

11. Anand SK. Role of mitochondria during bovine adenovirus $3[\mathrm{PhD}$ dissertation]. Saskatchewan: University of Saskatchewan; 2011. p.12. http://hdl.handle.net/10388/ETD-2011-11-283

12. Ahmet A k, and Kale M. Detecting the effect of Umckaloabo /Eps 7630 liquid extract after its therapeutic purposed usage in calves showing
تعد الاصدابات التنفسية في الابقار و التي تتجم عن المسببات الإتيات

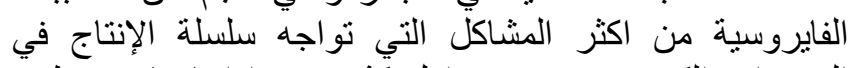

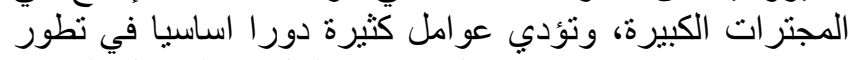

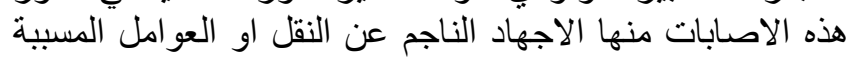

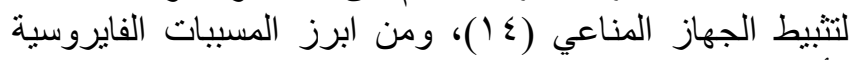

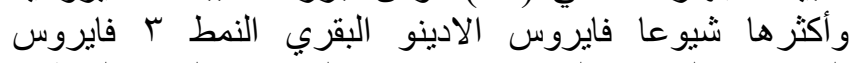

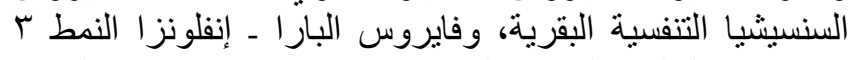

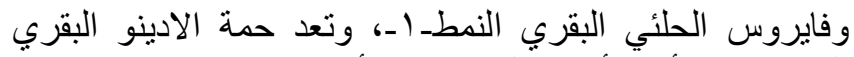

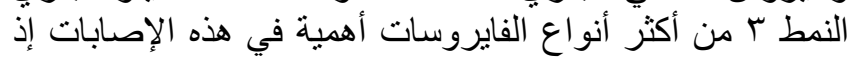

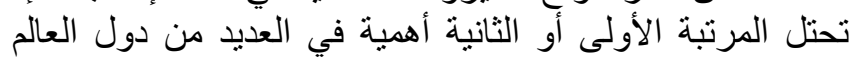

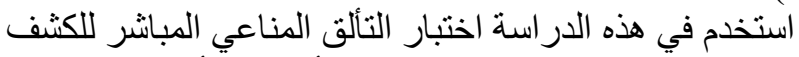

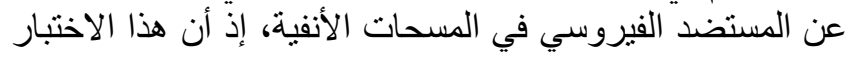

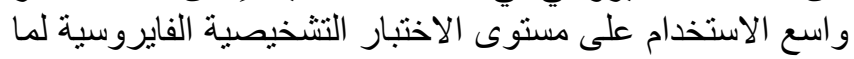

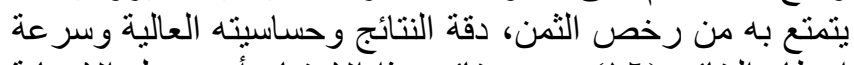

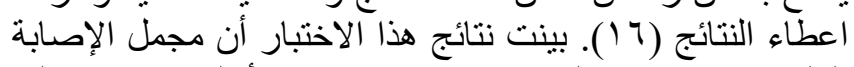

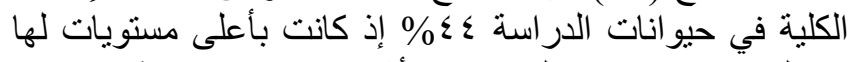

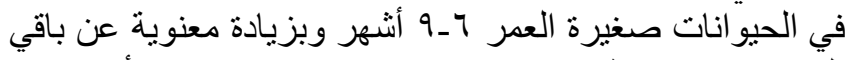

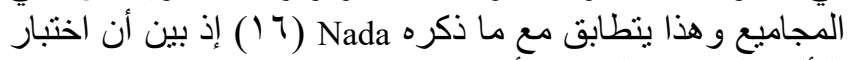

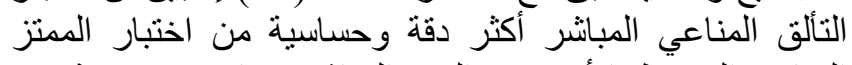

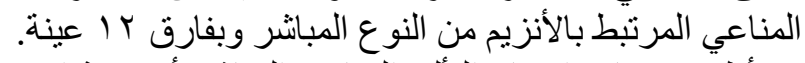

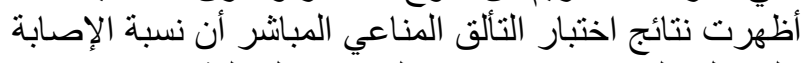

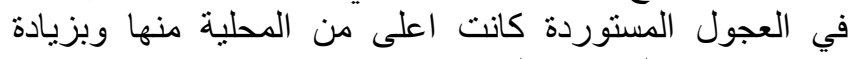

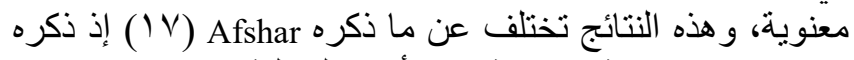

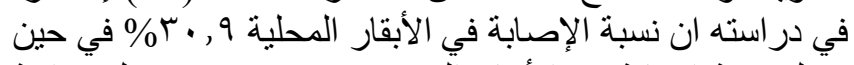

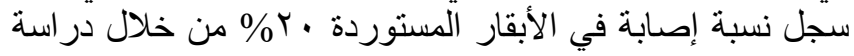

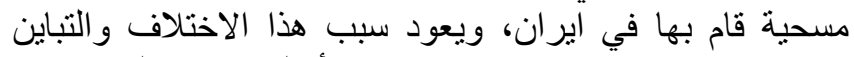

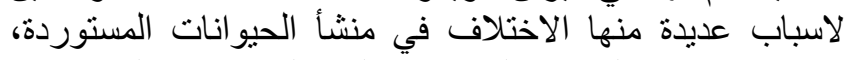

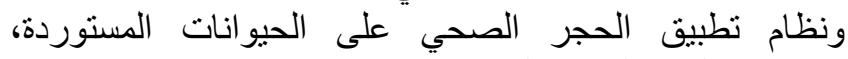

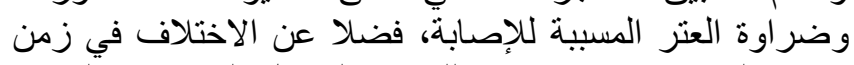

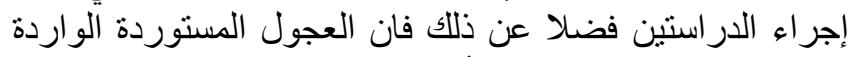

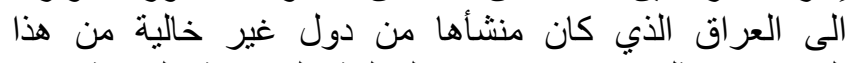

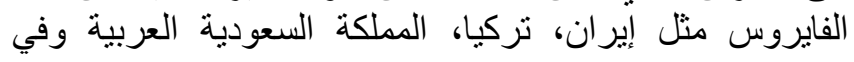

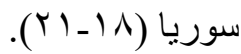
واظهرت النتائج ان نسبة الاصابة في الحيوانات التي تعاني

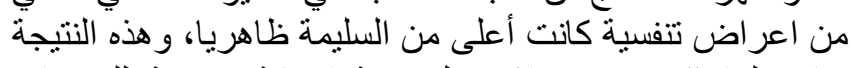

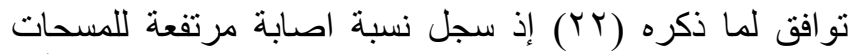

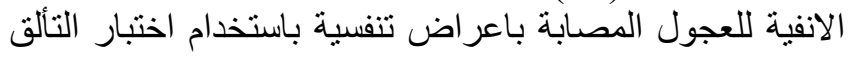

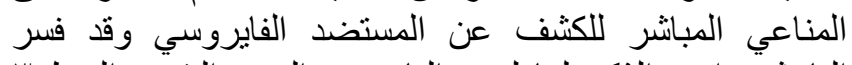

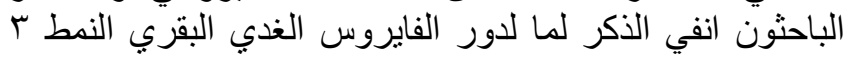

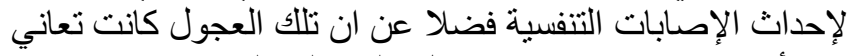

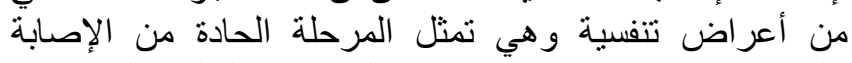
بالمرض، وتشير نسبة الإصـابة في الحيو انات السليمة الى الصابة الإبة 
18. Sakhaee E, Khalili M, Kazeminia S. Serological study of bovine viral respiratory diseases in dairy herds in Kerman province Iran. Iranian J Vet Res. 2009;10(1):49-53. 10.22099/IJVR.2009.1089

19. Kale M, Ozturk D, Hasircioglu S, Pehlivanoglu F, Turutoglu H. Some viral and bacterial respiratory tract infections of dairy cattle during the summer season. Acta Vet. 2013;63(2-3):2227-236. DOI:10.2298/AVB1303227K

20. Al-Hammadi MA, Hemida MG. Sero-Prevalence of common bovine respiratory viral diseases in Saudi Arabia. Med J. 2014;60(140):76-81. doi: 10.5455

21. Giangaspero M, Vacirca GV, Anopdenbosch E, Blondeel H. Epidemiological survey on viruses' diseases of cattle in north Syria. Trop Tura. 1992;10(2):55-57. http://agris.fao.org/agrissearch/search.do?recordID=BE9400202

22. Nada EM, Intisar KS, Selma BE, Ali YH. Epidemiology of cattle respiratory infection in Gezira State, Sudan: Serological evidence of adenovirus 3 infection. IJAVMS. 2015;9:289-299. https://pdfs.semanticscholar.org/c5ed/f7a4fb2319a5b688ebbd6d47f5570 cda48a4.pdf

23. Debey BM, Lehmkuhl HD, Chard C, Bergstrom L, Hobbs A. Ovine adenovirus serotype 7 associated mortality in lambs in the United States. Vet Pathol. 2011;38:644-648. doi.org/10.1354/vp.38-6-644. symptoms of respiratory tract infection. Acta Scand Vet. 2017;45:1-8. DOI: $10.22456 / 1679-9216.80475$

13. Rai A. Laboratory manual of cell culture and animal virology. Indian Vet Res Inst. 2008;1:8-12. http://ivri.nic.in/division/ah/biotech/ ScientistDetails.aspx?ID=161

14. Ceribasi AO, Ozkaraca M, Ceribasi S, Ozer H. Histopathologic immunoperoxidase and immunofluorescent examinations on natural cattle pneumonia originated from parainfluenza type3, respiratory syncytial virus, adenovirus type 3 and herpesvirus type 1 . Revue Med Vet. 2014;165:201-212. http://wwwi.vef.hr/vetarhiv/papers/2016-86-12.pdf.

15. Roshtkhari F, Mohammadi G, Mayameei A. Serological evaluation of relationship between viral pathogens (BHV-1, BVDV, BRSV, PI-3V, and Adeno3) and dairy calf pneumonia by indirect ELISA. Trop Anim Health Prod. 2012;41(3): 1105-1110. DOI: 10.1007/s1 1250-011-0046-4

16. Intisar K S, Ali Y H, Khalafalla A I, Taha K M, Mahasin E. Adenovirus type -3infection in camels in Sudan. Afr .J. microbial. Res, 2010.4 (13): 1356-1358 https://academicjournals.org/journal/AJMR/article-full-textpdf/5BF8F0913729.

17. Afshar A. The occurrence of precipitating antibodies to bovine adenoviruses in sera of farm animals and man in Iran. Vet Rec. 1969;84:571-572. DOI: $10.1136 / v r .84 .23 .571$ 